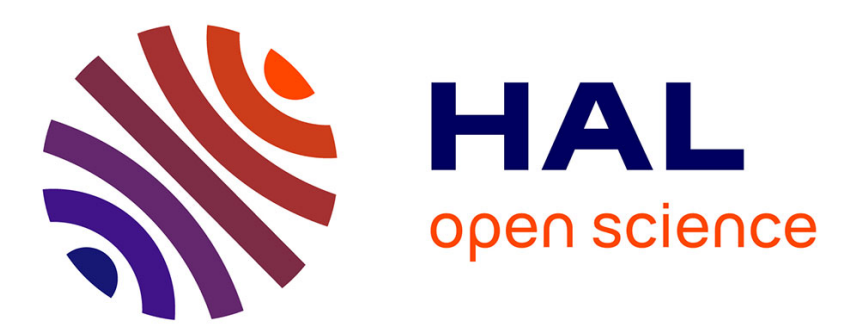

\title{
In-situ fabrication of polyacrylate-silver nanocomposite through photoinduced tandem reactions involving eosin dye
}

Lavinia Balan, Jean-Pierre Malval, Raphaël Schneider, Didier Le Nouen, Daniel Joseph Lougnot

\section{To cite this version:}

Lavinia Balan, Jean-Pierre Malval, Raphaël Schneider, Didier Le Nouen, Daniel Joseph Lougnot. Insitu fabrication of polyacrylate-silver nanocomposite through photoinduced tandem reactions involving eosin dye. Polymer, 2010, 51 (6), pp.1363-1369. 10.1016/j.polymer.2009.05.003 . hal-00785986

\section{HAL Id: hal-00785986 \\ https://hal.science/hal-00785986}

Submitted on 8 Feb 2013

HAL is a multi-disciplinary open access archive for the deposit and dissemination of scientific research documents, whether they are published or not. The documents may come from teaching and research institutions in France or abroad, or from public or private research centers.
L'archive ouverte pluridisciplinaire HAL, est destinée au dépôt et à la diffusion de documents scientifiques de niveau recherche, publiés ou non, émanant des établissements d'enseignement et de recherche français ou étrangers, des laboratoires publics ou privés. 


\title{
In situ fabrication of polyacrylate-silver nanocomposite through photoinduced tandem reactions involving eosin dye
}

\author{
Lavinia Balan $^{\mathrm{a}} *$, Jean-Pierre Malval $^{\mathrm{a}}$, Raphaël Schneider ${ }^{\mathrm{b}}$, Didier Le Nouen ${ }^{\mathrm{c}}$, Daniel-Joseph \\ Lougnot $^{\mathrm{a}}$
}

aápartement de Photochimie Générale, UMR CNRS 7525, Université de Haute Alsace, ENSCMu. 3 rue Alfred Werner, 68093 Mulhouse, France

${ }^{\mathrm{b}}$ Département de Chimie Physique des Réactions, Nancy University, CNRS, 1, rue Grandville, BP 20451, 54001 Nancy Cedex, France

${ }^{\mathrm{c}}$ Laboratoire de Chimie Organique et Bioorganique, UMR CNRS 7015, Université de Haute Alsace, ENSCMu. 3 rue Alfred Werner, 68093 Mulhouse, France

Corresponding authors: lavinia.balan@uha.fr

\begin{abstract}
A silver-acrylate nanocomposite was prepared using a novel one-pot strategy involving eosin dye as visible sensitizer and an amine derivative as radicals source. The mechanism highlighted by steady state photolysis and time resolved absorption spectroscopy lies on the initial formation of a strong ion pair complex between eosin and $\mathrm{Ag}^{+}$. Upon visible irradiation, the excited triplet state of the metal complex efficiently abstracts a hydrogen atom from the amine and produces a $\alpha$-aminoalkyl radical. In acrylate monomer matrix, such a strong reactive species initiates a free radical photopolymerization and also provides the reduction of the silver cation. Through this 'in-situ' fabrication method, the kinetics formation of the nanocomposite and its detailed structural analysis are characterized by UV-Visible, real-time FTIR absorption spectroscopy and by transmission electron microscopy.
\end{abstract}

Keywords: Nanocomposite, Silver nanoparticles, Eosin 


\section{Introduction}

Progresses in size- and shape-selective synthetic routes to produce metal nanoparticles have become the subject of extensive investigations over past decade. Their size-dependent physical properties[1,2] clearly constitute one of the most attractive aspect which has promoted the emergence of a very large set of applications in optics,[3-6] microelectronics, $[7,8]$ high density data storage, $[9,10]$ catalysis $[11,12]$ and energy conversion.[13,14] Nanocomposite materials, which combine the properties of polymers and silver nanoparticles, are considered to be promising systems for advanced functional applications.[15] For instance, coaxial nanocables[16] with a nanometric silver core and covered by a polymer shell exhibit superior performance as nanocircuits[8] or nanosenors.[7] Such nanowires can be synthesized by either solution-phase methods using capping reactants[17,18] or by templating methods using inorganic porous material,[19] polymer membranes,[20,21] or block copolymer.[22] Another type of nanocomposites consists in a dispersion of metal particles into a polymeric matrix such as poly(vinyl alcohol),[23,24] poly(methyl methacrylate)[25] or poly(vinyl pyrrole) for instance.[26,27] Typically, in-situ and ex-situ methods[28-30] are the two main synthetic routes that lead to silver-polymer nanocomposites. The ex-situ method consists in dispersing dry silver nanoparticles produced beforehand by an appropriated chemical process into a polymer medium to generate highly ordered periodic arrays of nanoparticles.[31] In the in-situ method, metal nanoparticles are generated directly in the matrix through chemical reduction of a cationic precursor previously dissolved in the bulk.[24] Photochemical reduction by irradiating a dye sensitizer in the presence of silver ions also provides a convenient way to produce embedded nanoparticles in polymer.[21,32-35] Moreover, a concomitant functionalization of the nanoparticles with dyes can occur, which is a valuable feature for applications in photochemical solar cells.[14,36] In all cases, the high-performance of nanomaterials depends on the controlled distribution of uniformly shaped and sized particles. Therefore, the development of synthetic strategies to control particles growth and/or agglomeration during nanocomposite fabrication appears quite obviously as a key challenge.

The present work reports a strategy involving the photoinduced formation of homogeneous silver nanoparticles in a polyacrylate polymer stemming from a cross linking photopolymerization of pentaerythritol triacrylate monomer (Scheme 1a). In this one-step approach, a combined system employing eosin dye as visible photosensitizer (Scheme 1b) and 
$\mathrm{N}$-methyl diethanolamine as co-initiator is used to photogenerate Ag nanoparticles and to photoinitiate a free radical polymerization at the same time. After a mechanistic insight provided by steady state and laser flash photolysis experiments, the analysis of the elementary steps leading to the metal nanocomposite will be correlated to the structural properties of the materials.

\section{Experimental section}

\subsection{Reagents}

Silver nitrate $\left(\mathrm{AgNO}_{3}\right)$ with a purity $>99 \%$ was purchased from Fluka. Eosin Y disodium salt, $\mathrm{N}$-methyl diethanolamine (MDEA), tetra-n-butylamonium hexafluoroborate were purchased from Aldrich. Mixture of pentaerythritol tri- and tetra-acrylate (PETA) monomers stabilized with monomethyl ether hydroquinone (MEHQ - 400 ppm) was purchased from Sartomer. All solvents were Aldrich and Fluka Spectrograde.

\subsection{Instrumentation}

The absorption measurements were carried out with a Perkin Elmer Lambda 2 spectrometer. A FluoroMax 4 Luminescence Spectrometer was used for the fluorescence and time gated phosphorescence. Low temperature measurements were performed in a glassy matrix of isopropanol using a 5-mm diameter quartz tube inside a Dewar filled with liquid nitrogen. The emission spectra were spectrally corrected in all cases.

Laser flash photolysis at nanosecond time scale was carried out with an Edinburgh Analytical Instruments LP900 equipped with a 450-W pulsed Xe arc lamp, a Czerny-Turner monochromator and a fast photomultiplier. The samples were irradiated with the second harmonic $(\lambda=532 \mathrm{~nm}, \sim 10 \mathrm{~ns}, 4 \mathrm{~mJ}$ per pulse) of a Nd/YAG Powerlite 9010 from Continuum. The sample was purged with argon for $15 \mathrm{~min}$ prior to photophysical studies. The acrylate formulation, typically Eosin (0.1 wt \%), MDEA (3\% wt) and $\mathrm{AgNO}_{3}(1 \mathrm{wt} \%)$ in PETA, was sandwiched between two glass plates with a calibrated thickness spacer setting the optical path length to $30 \mu \mathrm{m}$. Photochemical reactions were carried out at $532 \mathrm{~nm}$ with a cw $532 \mathrm{~nm}$ Verdi laser from Coherent. The progress of the reaction was monitored via UVVis absorption spectra. 
The photopolymerization was followed up in situ by real-time Fourier transformed infrared spectroscopy with an AVATAR 360 FTIR spectrometer from Nicolet. The laminated formulation ( $25 \mu \mathrm{m}$ thick), deposited on a $\mathrm{BaF}_{2}$ pellet, were irradiated at $532 \mathrm{~nm}$ with a green laser diode module from Crystalaser. The conversion rates were deduced from the disappearance of the vinyl $\mathrm{C}=\mathrm{C}$ stretching vibration band at $1630 \mathrm{~cm}^{-1}$.

Transmission electron microscopy (TEM) was used to characterize the size and shape of Ag nanoparticles. The nanocomposites were cut by means of a microtome (LKB model 8800) and placed onto the observation grid to get their TEM images. Transmission electron microscopy measurement is carried out at $200 \mathrm{kV}$ using a Philips CM20 instrument with Lab6 cathode.

The ${ }^{13} \mathrm{C}$ NMR spectra were recorded in $\mathrm{CD}_{3} \mathrm{CN}$ on a $400 \mathrm{MHz}$ Brucker NMR spectrometer using cyclohexane as the internal standard.

\section{Results and discussion}

\subsection{Formation of a strong ion-pair complex with $\mathrm{Ag}^{+}$}

The lowest energy absorption band of $\mathrm{EO}^{2-}$ is localized in the $450-575 \mathrm{~nm}$ region with a maximum at $530 \mathrm{~nm}$ in acetonitrile (Figure 1). This band corresponds to the $S_{0}-S_{1}$ electronic transition with a $\pi-\pi^{*}$ character localized on the xanthene moiety.[37] The geometry optimization by AM1 method reveals that 2-benzoate and xanthene sub-units are twisted with an angle of $77^{\circ}$, which indicates a weak electronic conjugation between the two aromatic moieties. The fluorescence spectrum of $\mathrm{EO}^{2-}$ is mirror image of its absorption band with a slight Stockes shift $\left(535 \mathrm{~cm}^{-1}\right)$ suggesting a weak geometrical relaxation in the singlet state. The 0-0 transition energy measured from the intercept of normalized absorption and fluorescence spectra corresponds to $2.31 \mathrm{eV}$ in acetonitrile. The phosphorescence spectrum of $\mathrm{EO}^{2-}$ is located in the $600-700 \mathrm{~nm}$ range with a maximum emission at $652 \mathrm{~nm}$ which leads to a triplet energy of about $1.90 \mathrm{eV}$ (inset figure 1).

As depicted in figure 2, the addition of silver nitrate to a solution of $\mathrm{EO}^{2-}$ in acetonitrile leads to a slight red shift of the last absorption band of the chromophore $\left(\Delta \lambda_{\max }=+4 \mathrm{~nm}\right)$. The presence of two isosbestic points located at $498 \mathrm{~nm}$ and $530 \mathrm{~nm}$ clearly indicates the occurrence of equilibrium reaction. Moreover, the addition of tetra-n-butylamonium hexafluoroborate $\left(3 \times 10^{-2} \mathrm{M}\right)$ excludes any variation of the ionic strength during the reaction. Therefore we can ascribe these effects to a coordination reaction of $\mathrm{Ag}^{+}$by $\mathrm{EO}^{2-}$ which leads 
to the formation ion-pair complex [EO-Ag] $]^{-}$According to the stronger acidic character of the hydroxylic group with respect to that of the carboxylic one[38,39], such a cation exchange reaction should mainly involve the chelation of silver cation by the 'phenolate' oxygen. This is also in line with the Pearson's hard-soft acid-base (HSAB) principle[40-43] which presumes a better stabilizing interaction of $\mathrm{Ag}^{+}$(Soft Lewis acid) with the phenolate group than with the carboxylate function. However the participation of the carboxylate function to the coordination reaction can not be excluded. In order to determine the reaction constants, the absorption changes as a function of the concentration of $\mathrm{AgNO}_{3}$ were analyzed according to the model proposed by Valeur et al[44] which is extended to the formation of [1:1] and [1:2] ligand-metal complexes[45]. The inset Figure 2 depicts the best-fitting curve to the experimental data using the method of least squares, $\log \mathrm{K}_{1: 1}$ exhibits a high value of ca. $4.7 \pm$ 0.3 whereas $\log K_{1: 2}$ has a value of ca. $5.0 \pm 0.4$. Such a slight difference suggests that the formation of the [1:2] complex can be reasonably neglected with respect to our working condition (i.e. $\left.\left[\mathrm{Ag}^{+}\right] /\left[\mathrm{EO}^{2-}\right]<50\right)$.

\subsection{Mechanistic aspect of Ag nanoparticles photogeneration in solution}

Figure 3 shows the evolution of the transient absorption spectrum of $\mathrm{EO}^{2-}$ in acetonitrile. The spectrum mainly consists of a broad band located in the 560-700 $\mathrm{nm}$ range. This band was previously assigned[46-48] to the absorption of the triplet of $\mathrm{EO}^{2-}\left({ }^{3} \mathrm{EO}^{2-}\right)$, its transient monitored at $580 \mathrm{~nm}$ decays mono-exponentially with a lifetime of $45 \mu \mathrm{s}$. The spectrum also exhibits a bleaching in the $520 \mathrm{~nm}$ region which corresponds to the depletion of the ground state. The transient absorption spectrum below $490 \mathrm{~nm}$ corresponds to the superimposition of the absorption of three species: the triplet of eosin, the semi-oxidized (EO $\left.{ }^{\circ}\right)$ and semi-reduced $\left(\mathrm{EO}^{\cdot 3-}\right)$ radical ions. The two latter species are generated through a self-quenching of ${ }^{3} \mathrm{EO}^{2-}$ by ground state molecules:

$$
\begin{gathered}
{ }^{3} \mathrm{EO}^{2-}+\mathrm{EO}^{2-} \rightarrow \mathrm{EO}^{2-}+\mathrm{EO}^{2-} \\
{ }^{3} \mathrm{EO}^{2-}+\mathrm{EO}^{2-} \rightarrow \mathrm{EO}^{--}+\mathrm{EO}^{\cdot 3-}
\end{gathered}
$$

In acetonitrile, these long-lived radical ions are known[47,48] to have strongly overlapped absorption bands. The maximum absorption wavelength of $\mathrm{EO}^{\cdot 3-}$ is reported at $430 \mathrm{~nm}$ (49) whereas EO`- shows a band centred at $450 \mathrm{~nm}(39,50)$.

The addition of 50 eq. of $\mathrm{Ag}^{+}$to a solution of $\mathrm{EO}^{2-}$ leads to a quantitative conversion of the dye to its ion-pair complex, [EO-Ag] $]^{-}$As shown in Figure 4, the transient absorption 
spectrum remains globally invariant for wavelength above $490 \mathrm{~nm}$. The triplet lifetime measured from the transient at $580 \mathrm{~nm}$ drops to a value of $25 \mu \mathrm{s}$. Consecutive to the triplet quenching, the development of a long time component is observed in the transient monitored at $450 \mathrm{~nm}$ (inset Figure 4) which indicates the growth of a new band in this spectral window. This band can be confidently assigned to the absorption of semi-oxidized eosin as compared with that observed by Lindqvist (47) and Grossweiner $(48,50,51)$. Besides, the transient absorption spectrum exhibits an other band centred at $370 \mathrm{~nm}$. Such a broad band which collapses within the first $2 \mu$ s after laser pulse corresponds to the well-established band of $\mathrm{Ag}^{0}$ $(17,52,53)$. Hence we have a clear evidence of a photoinduced electron transfer from ${ }^{3} \mathrm{EO}^{2-}$ to $\mathrm{Ag}^{+}$. However, probably due to its relative low reaction rate, such a process can not produce efficiently silver nanoparticles. This is confirmed by steady state photolysis experiment. The changes in the spectral features observed upon laser excitation of eosin dye and $\mathrm{AgNO}_{3}(50$ eq.) solution in acetonitrile are depicted in Figure 5A. Upon increasing the irradiation time, the absorption band of $\mathrm{EO}^{2-}$ is progressively collapsing, however we fail to observe the formation of silver nanoparticles. The same photolysis experiment is performed with a solution of acetonitrile containing eosin dye, $\mathrm{AgNO}_{3}$ and MDEA. In this case, a new band centred around $435 \mathrm{~nm}$ and characteristic of the surface plasmon (SP) band of silver nanoparticles is clearly developing (Figure 5B). Obviously, the reduction of $\mathrm{Ag}^{+}$in presence of MDEA is only possible with $\mathrm{EO}^{2-}$ and under visible irradiation. This confirms that the formation of silver nanoparticles is promoted by the excited dye and its mediating role with MDEA. The amine is known to undergo a hydrogen abstraction reaction with the triplet state of eosin $\left({ }^{3} \mathrm{EO}^{2-}\right)$. The sequential reaction first involves an electron transfer reaction from amine to ${ }^{3} \mathrm{EO}^{2-}$ then a proton transfer within ion pair formed between amine radical cation and eosin radical anion $(49,54)$. Hence, the reaction should initially produce a $\alpha$-aminoalkyl radical and the conjugated acid of the semi-reduced eosin $\left(\mathrm{EOH}^{-2-}\right)$. However the latter species which exhibits a transient absorption band around $375 \mathrm{~nm}$ is in equilibrium with its conjugate base $\mathrm{EO}^{\cdot 3-}$ whose absorption band is located at $430 \mathrm{~nm}$. The equilibrium has been observed on flash photolysis of $\mathrm{EO}^{2-}$ in aqueous media, with a $\mathrm{pK}_{\mathrm{a}}$ of 7 associated with the acidic form $(47,48,51)$. The bimolecular quenching rate constant of ${ }^{3} \mathrm{EO}^{2-}$ by $\operatorname{MDEA}\left(\mathrm{k}_{\mathrm{q}}\right)$ can be determined from the dependence of the pseudo-first-order decay of the triplet dye on the concentration of MDEA according to the equation:

$$
\mathrm{k}_{\mathrm{obs}}=\mathrm{k}_{0}+\mathrm{k}_{\mathrm{q}}[\mathrm{MDEA}]
$$


In this condition, the bimolecular quenching rate exhibits a value of $2.5( \pm 0.1) \times 10^{6} \mathrm{M}^{-1} \mathrm{~s}^{-1}$, in good accordance with literature (54). This low rate constant suggests typical hydrogen atom transfer reaction instead of electron-proton transfer sequence. Parallely to the quenching of triplet eosin, $\mathrm{EO}^{\cdot 3-}$ is detected at $430 \mathrm{~nm}$. This indirectly confirms the production of the $\alpha$ aminoalkyl radical which can not be detected in the spectral window provided by laser flash photolysis.

Figure 6 shows the evolution of the transient absorption spectrum of a solution containing $\mathrm{EO}^{2-}, \mathrm{AgNO}_{3}$ and MDEA. At very short delay after laser pulse, the absorption band of $\mathrm{Ag}^{0}$ located at $370 \mathrm{~nm}$ reaches its maximum, its transient can be confidently fitted with one exponential leading to a short lifetime of $290 \mathrm{~ns}$. Interestingly, the fast decrease of the metal absorption band reveals the presence of a weak band at $375 \mathrm{~nm}$ which is ascribable to the absorption of $\mathrm{EOH}^{\cdot 2-}$. As the intensive transient absorption band of $\mathrm{EO}^{\cdot 3-}$ is concomitantly developing, we have clear indication that the reduction of $\mathrm{Ag}^{+}$does not proceed through the oxidation of $\mathrm{EO}^{\cdot 3-}$ but through an electron transfer from the $\alpha$-aminoalkyl radical. Carboncentred free radicals with adjacent nitrogen or oxygen are potent reducing agents in solution[55-59]. For instance, it has been reported that the photogenerated alkoxy benzyl radicals[33] or ketyl radicals[60] can convert efficiently $\mathrm{Ag}^{+}$to $\mathrm{Ag}^{0}$. Hence, we can assume that the main reaction route leading to the generation of Ag nanoparticles can be described as follows :

$$
\begin{gathered}
{ }^{3}[\mathrm{EO}-\mathrm{Ag}]^{-}+\mathrm{MDEA} \rightarrow \mathrm{EOH}^{\cdot 2-}+\mathrm{Ag}^{+}+\mathrm{MDEA}^{\bullet} \\
\mathrm{Ag}^{+}+\mathrm{MDEA}^{\cdot} \rightarrow \mathrm{Ag}^{0}+\mathrm{MDEA}^{+}
\end{gathered}
$$

The initial coordination of eosin dye with silver cation undoubtedly constitutes an advantage since the photogeneration of the $\alpha$-aminoalkyl radical and its consecutive oxidation by $\mathrm{Ag}^{+}$ are occurring in the same reactive cage. In PETA monomer, the ion-pair complex formation appears all the more useful as its presence should strongly counterbalance the effect of a slow diffusion in high viscous medium.

\subsection{Reduction of $\mathrm{Ag}^{+}$ions in a PETA matrix}

The fabrication of metal nanocomposite is performed using pentaerythritol triacrylate (PETA) as monomer. Surprisingly, the dilution of $\mathrm{AgNO}_{3}$ in PETA matrix leads to a very slow change in colour. The absorption spectrum of the formulation clearly shows the growth of a band centred at $435 \mathrm{~nm}$ which corresponds to the SP band of Ag nanoparticles (inset Figure 7). The 
TEM image of the sample indicates a polydisperse distribution of spherical silver nanoparticles (Figure 7). Hence a reduction of silver cations is occurring in the monomer. The involvement of MEHQ (used as monomer stabilizer) in this reaction can be excluded since no reduction was detected upon addition of large amount of this phenol derivative to a solution of the silver salt in acetonitrile. Therefore the pentaerythritol triacrylate induces a slow reduction of $\mathrm{Ag}^{+}$. Moreover, the ${ }^{13} \mathrm{C}$ NMR spectrum of the monomer in acetonitrile- $d_{3}$ is notably modified in the presence of $\mathrm{Ag}^{+}$. While main part of the NMR spectrum remains invariant in presence of $\mathrm{Ag}^{+}$, the signals of vinylic carbons[61] are gradually shifted by increasing the concentration of $\mathrm{AgNO}_{3}$. For instance, upon addition of 10 eq. of $\mathrm{Ag}^{+}$, the signal of methylene carbons $(\delta=131.51 \mathrm{ppm})$ is shifted to low-field region $(+0.2 \mathrm{ppm})$ whereas the methine one $(\delta: 128.29 \mathrm{ppm})$ shifts to high-field region $(-0.2 \mathrm{ppm})$. It should be noted that $\mathrm{Ag}^{+}$is wellknown to form complexes with a large set of alkenes[62-64], including methyl acrylate derivatives[65]. Therefore, the formation of a class $\mathrm{T} \square$ complex[64] between $\mathrm{Ag}^{+}$and PETA is proposed. Such a structure implies a trigonal environment around $\mathrm{Ag}^{+}$with a chelation of the cation by the three vinylic functions. As consequence, the close proximity between the hydroxyl group of PETA and $\mathrm{Ag}^{+}$should promote a redox reaction and lead to the formation of $\mathrm{Ag}$ nanoparticles. The oxidation of primary alcohols $\left(\mathrm{R}-\mathrm{CH}_{2} \mathrm{OH}\right)$ by $\mathrm{Ag}^{+}$is also well established, the reaction is slow and requires heating to be accelerated as follows[66-68] :

$$
2 \mathrm{Ag}^{+}+\mathrm{R}-\mathrm{CH}_{2} \mathrm{OH} \rightarrow 2 \mathrm{Ag}^{0}+2 \mathrm{H}^{+}+\mathrm{R}-\mathrm{CHO}
$$

However such a reaction is a very slow process and constitutes a minor route for $\mathrm{Ag}^{+}$ reduction in comparison with the photoinduced generation of $\mathrm{Ag}$ nanoparticles described hereafter.

\subsection{Fabrication of silver nanoparticle embedded polymer}

A formulation of the PETA monomer containing $\mathrm{EO}^{2-}(0.1 \mathrm{wt} \%)$ and MDEA (3\% $\%$ w) [69] and $\mathrm{AgNO}_{3}(1 \mathrm{wt} \%)$ is photopolymerized upon irradiation at $532 \mathrm{~nm}\left(2.5 \mathrm{~mW} \mathrm{~cm}{ }^{-2}\right)$. The conversion of the acrylate double bonds was monitored from the decrease of the IR band at $1630 \mathrm{~cm}^{-1}$. In Figure 8 are compared the conversion rate related to this formulation with that of a reference one without $\mathrm{AgNO}_{3}$. Both samples show a similar rate of polymerization (within our experimental error) with an acrylate final double bond conversion of about $60 \%$. This final degree of double bond conversion should be ascribed to the acrylate trifunctionality. As the functionality increased, the viscosity of the resin increased, with the 
resulting gel-effect and the higher cross linked density, set a limit to the extent of conversion[70]. We can clearly notice that the addition of $\mathrm{Ag}^{+}$does not perturb the photopolymerization kinetics. Therefore, the quantum yield of generation of $\mathrm{MDEA}^{*}$ is sufficiently high to enable the free radical photoinitiation and the photogeneration of $\mathrm{Ag}$ nanoparticles. Moreover after $10 \mathrm{~min}$ exposure, the reference sample turns from pink to colourless whereas the sample with $\mathrm{Ag}^{+}$turned from pink to yellowish (inset Figure 8).

The absorption spectrum of the sample undergoes important changes during visible irradiation (Figure 9). The absorption band of $\mathrm{EO}^{2-}$ decreased progressively whereas the SP developed in the $350-500 \mathrm{~nm}$ region. This band exhibited a maximum wavelength at $437 \mathrm{~nm}$ with a FWHM of $115 \mathrm{~nm}$. Careful analysis of the absorption spectrum over the illumination period clearly reveals a two-step process :

(i) The first step corresponds to the photobleaching of $\mathrm{EO}^{2-}$ with the concomitant growth of the surface plasmon band as indicated by the linear correlation between the absorbance at $532 \mathrm{~nm} v s$. absorbance at $432 \mathrm{~nm}$ (inset of Figure 9).

(ii) In a second step, the SP band continues to develop under irradiation even though the absorption band of $\mathrm{EO}^{2-}$ has completely disappeared. Small particles formed in the first step contribute to the further reduction of $\mathrm{Ag}^{+}$through an autocatalytic process where the residual PETA monomers should act as sacrificial donor. Ultimately, the absorbance of SP stabilized to ca twice that measured at the end of $\mathrm{EO}^{2-}$ bleaching.

Figure 10 shows the linear correlation between the final absorbance reached by the SP band at its maximum and the initial amount of $\mathrm{EO}^{2-}$; this correlation suggests that the initial step determines the final concentration of nanoparticles in the polymer. The bright field TEM micrographs of silver-nanocomposites displayed in Figure 11 corroborate the correlation between the density of nanoparticles and the initial amount of $\mathrm{EO}^{2-}$. Throughout the photoreduction process, the symmetrical shape of the SP band denotes a monodisperse size distribution of the silver nanoparticles. Electron microscopy analysis of the polymer indicated the formation of monodisperse spherical metallic particles in nanometer range size. Analysis of a population of ca. hundred particles from a portion of the grid indicated that their average diameter is $5.0 \pm 0.9 \mathrm{~nm}$ respectively $5.0 \pm 0.7 \mathrm{~nm}$. The particles were homogeneous in size and no agglomeration was observed. Such a homogeneous distribution can be accounted by the stabilizing effect of the PETA matrix. Through its acrylate functions, the PETA monomer can easily adsorb on the nanoparticle surface. In this regards, the capping effect of unsaturated long-chain agents was previously observed by Wang et al.[71], who correlated the size of silver particles with the number of double bonds in the chain. 


\section{Conclusion}

A strong ion pair complex is formed at the ground state between eosin dianion chromophore and $\mathrm{Ag}^{+}$. The triplet state of such a metal complex dye conserves its high hydrogen abstraction propensity toward N-methyl diethanolamine. The $\alpha$-aminoalkyl radicals that are consequently produced upon visible irradiation lead to a consecutive reduction of the coordinated silver cations. Moreover, in triacrylate monomer matrix, the quantum yield of radicals generation is still high and allows a simultaneous free radical polymerization. Hence, an "in situ" synthesis of silver nanoparticle embedded polymer is clearly demonstrated with the advantage that the particles density in the polymer can be tuned by controlling the initial concentration of dye. Finally, the obtained nanocomposite exhibits spherical shaped Ag nanoparticles whose homogeneous dispersion is ascribable to the capping effect of monomer acrylate branches that are not engaged in the polymer net. 


\section{References}

[1] Eustis, S.; El-Sayed, M. A. Chem. Soc. Rev. 2006, 35, 209-217.

[2] El-Sayed, M. A. Acc. Chem. Res. 2001, 34, 257-264.

[3] Jin, R. C.; Cao, Y. W.; Mirkin, C. A.; Kelley, K. L.; Schatz, G. C.; Zheng, J. G. Science 2001, 294, 1901.

[4] U.Kreibig; M.Vollmer. Optical Properties of Metal Clusters; Springer-Verlag: Berlin, 1995.

[5] Ung, T.; Liz-Marzàn, L. M.; Mulvaney, P. J. Phys. Chem. B 2001, 105.

[6] Balan, L.; Schneider, R.; Lougnot, D. J. Prog. Org. Coat. 2008, 62, 351-357.

[7] Duan, X.; Huang, Y.; Cui, Y.; Wang, J.; Lieer, C. M. Nature 2001, 409, 66-69.

[8] Holmes, J. D.; Johnston, K. P.; Doty, R. C.; Korgel, B. A. Science 2000, 287, 14711473.

[9] Ouyang, J.; Chu, C.-W.; Sieves, D.; Yang, Y. Appl. Phys. Lett. 2005, 86, 123507.

[10] Ouyang, J.; Chu, C.-W.; Szmanda, C. R.; Ma, L.; Yang, Y. Nat. Mat. 2004, 3, 918922.

[11] Jiang, Z.-J.; Liu, C.-Y.; Sun, L.-W. J. Phys. Chem. B 2005, 109, 1730-1735.

[12] Narayanan, R.; El-Sayed, M. A. J. Phys. Chem. B 2005, 109, 12663-12676.

[13] Lahav, M.; Gabriel, T.; Shipway, A. N.; Willner, I. J. Am. Chem. Soc. 1999, 121, 258259.

[14] Thomas, K. G.; Kamat, P. V. Acc. Chem. Res. 2003, 36, 888-898.

[15] Armelao, L.; Barreca, D.; Bottaro, G.; Gasparotto, A.; Gross, S.; Maragno, C.; Tondello, E. Coord. Chem. Rev. 2006, 250, 1294.

[16] Luo, L.-B.; Yu, S.-H.; Qian, H.-S.; Zhou, T. J. Am. Chem. Soc. 2005, 127, 2822-2823.

[17] Pillai, Z. S.; Kamat, P. V. J. Phys. Chem. B 2004, 108.

[18] Wang, W.; Chen, X.; Efrima, S. J. Phys. Chem. B 1999, 103, 7238-7246.

[19] Masuda, H.; Fukuda, K. Science 1995, 268, 1466-1468.

[20] Cepak, V. M.; Martin, C. R. J. Phys. Chem. B 1998, 102, 9985-9990.

[21] Korchev, A. S.; Bozack, M. J.; Slaten, B. L.; Mills, G. J. Am. Chem. Soc. 2004, 126, $10-11$.

[22] Cornelissen, J. J. L. M.; Heerbeek, R. v.; Kamer, P. C. J.; Reek, J. N. H.; Sommerdijk, N. A. J. M.; Nolte, R. J. M. Adv. Mater. 2002, 14, 489-492.

[23] Gaddy, G. A.; Korchev, A. S.; McLain, J. L.; Slaten, B. L.; Steigerwalt, E. S.; Mills, G. J. Phys. Chem. B 2004, 108, 14850-14857.

[24] Porel, S.; Singh, S.; Harsha, S. S.; Rao, D. N.; Radhakrishnan, T. P. Chem. Mater. 2005, 17, 9-12.

[25] Kong, H.; Jang, J. Chem. Commun. 2006, 3010-3012.

[26] Chen, A.; Kamata, K.; Nakagawa, M.; Iyoda, T.; Wang, H.; Li, X. J. Phys. Chem. B 2005, 109, 18283-18288.

[27] Pinter, E.; Patakfalvi, R.; Fulei, T.; Gingl, Z.; Dekany, I.; Visy, C. J. Phys. Chem. B 2005, 109, 17474-17478.

[28] Balan, L.; Malval, J.-P.; Schneider, R.; Burget, D. Mat. Chem. Phys. 2007, 104, 417421.

[29] Carotenuto, G.; Nicolais, L.; Mortorana, B.; Perlo, P. Metal-Polymer Nanocomposites; John Wiley and Sons: New Jersey, 2004. 
[30] Balan, L.; Burget, D. Euro. Polym. J. 2006, 42, 3180-3189.

[31] Lim, M. H.; Ast, D. G. Adv. Mater. 2001, 13, 718-721.

[32] Balan, L.; Jin, M.; Malval, J.-P.; Chaumeil, H.; Defoin, A.; Vidal, L. Macromolecules 2008, 41, 9359-9365.

[33] Sangermano, M.; Yagci, Y.; Rizza, G. Macromolecules 2007, 40, 8827-8829.

[34] Sudeep, P. K.; Kamat, P. V. Chem. Mater. 2005, 17, 5404-5410.

[35] Yagci, Y.; Sangermano, M.; Rizza, G. Polymer 2008, 49, 5195-5198.

[36] Li, W.; Lynch, V.; Thompson, H.; Fox, M. A. J. Am. Chem. Soc. 1997, 119, 7211 7217.

[37] Pelet, S.; Grätzel, M.; Moser, J.-E. J. Phys. Chem. B 2003, 107, 3215.

[38] Levillain, P.; Fompeydie, D. Anal. Chem. 1985, 57, 2561-2563.

[39] Moser, J.; Grätzel, M. J. Am. Chem. Soc. 1984, 106, 6557-6564.

[40] Pearson, R. G. J. Am. Chem. Soc. 1963, 85, 3533-3539.

[41] Pearson, R. G. J. Chem. Educ. 1968, 45, 581-587.

[42] Pearson, R. G. J. Chem. Educ. 1968, 45, 643-648.

[43] Perason, R. G. J. Chem. Educ. 1987, 64, 561-567.

[44] Bourson, J.; Pouget, J.; Valeur, B. J. Phys. Chem. 1993, 97, 4552-4557.

[45] Malval, J.-P.; Lapouyade, R. Helv. Chim. Acta 2001, 84, 2439-2451.

[46] Gak, V. Y.; Nadtochenko, V. A.; Kiwi, J. J. Photochem. Photobio. A 1998, 116, $57-$ 62.

[47] Kasche, V.; Lindquist, L. Photochem. Photobiol. 1965, 4, 923.

[48] Zwicker, E. F.; Grossweiner, L. I. J . Phys. Chem. 1963, 67, 549.

[49] Jones, G.; Chatterjee, S. J. Phys. Chem. 1988, 92, 6862-6864.

[50] Kepka, A. G.; Grossweiner, L. I. Photochem. Photobiol. 1971, 14, 621.

[51] Chrysochoos, J.; Grossweiner, L. Photochem. Photobiol. 1968, 8, 193.

[52] Rele, M.; Kapoor, S.; Sharma, G.; Mukherjee, T. Phys. Chem. Chem. Phys. 2004, 6, 590-595.

[53] Janata, E.; Henglein, A.; Ershovt, B. G. J. Phys. Chem. 1994, 98, 10888-10890.

[54] Burget, D.; Fouassier, J. P.; Amat-Guerri, F.; Mallavia, R.; Sastre, R. Acta Polym. 1999, 50, 337-346.

[55] Kim, J. Y.; Shin, D. H.; Ihn, K. J. Macromol. Chem. Phys. 2005, 206, 794-801.

[56] Eksik, O.; Erciyes, A. T.; Yagci, Y. J. Macromol. Sci. , Part A 2008, 45, 698-704.

[57] Wayner, D. D. M.; Dannenberg, J. J.; Griller, D. Chem. Phys. Lett. 1986, 131, 189191.

[58] Wayner, D. D. M.; Griller, D. J. Am. Chem. Soc. 1985, 107, 7764-7765.

[59] Yagci, Y.; Hepuzer, Y. Macromolecules 1999, 32, 6367-6370.

[60] Scaiano, J. C.; Aliaga, C.; Maguire, S.; Wang, D. J. Phys. Chem. B 2006, 110, 1285612859.

[61] Newmark, R. A.; Palazzoto, J. Appl. Spect. 1990, 44, 804-807.

[62] Dongen, J. P. C. M. V.; Beverwijk, C. D. M. J. Organometal. Chem. 1973, 51, 36-38.

[63] Rathore, R.; Chebny, V. J.; Abdelwahed, S. H. J. Am. Chem. Soc. 2005, 127, 80128013.

[64] Hartley, F. R. Chem. Rev. 1973, 73, 163-189.

[65] Fueno, T.; Kajimoto, O.; Furukawa, J. Bull. Chem. Soc. Jap. 1968, 41, 782.

[66] Kim, J. S. J. Ind. Eng. Chem. 2007, 13, 718-722.

[67] Hah, H. J.; Koo, S. M.; Lee, S. H. J. of Sol-Gel Sci. Tech. 2003, 26, 467-471.

[68] Xiong, Y.; Siekkinen, A. R.; Wang, J.; Yin, Y.; Kim, M. J.; Xia, Y. J. Mat. Chem. 2007, 17, 2600-2602.

[69] Espanet, A.; Ecoffet, C.; Lougnot, D. J. J Polym Sci A: Polym Chem 1999, 37, $2075-$ 2085. 
[70] Mehnert, R.; Pincus, A.; Janorsky, I.; Stowe, R.; Berejka, A. In Chemistry \& Technology of UV \& EB Formulation for Coatings, Inks \& Paints; SITA Technology Ltd.: London, 1997, p 217.

[71] Wang, X.; Naka, K.; Itoh, H.; Park, S.; Chujo, Y. Chem. Commun. 2002, 1300-1301.

\section{FIGURES AND SCHEMES CAPTIONS}

Figure 1: Normalized absorption and fluorescence spectra of $\mathrm{EO}^{2-}$ in acetonitrile. Inset : Time-gated phosphorescence spectrum of $\mathrm{EO}^{2-}$ in glassy matrix of isopropanol (delay : $50 \mu \mathrm{s})$

Figure 2: Evolution of the absorption spectrum of $\mathrm{EO}^{2-}\left(2.4 \times 10^{-6} \mathrm{M}\right)$ upon addition of $\mathrm{AgNO}_{3}$ (solvent : acetonitrile, $[\mathrm{MDEA}]=10^{-4} \mathrm{M},\left[\mathrm{nBu}_{4} \mathrm{~N}, \mathrm{BF}_{6}\right]=3 \times 10^{-2} \mathrm{M}$ ) Inset : Dependence of the absorbance at $535 \mathrm{~nm}$ vs. concentration of silver cations (squares). Best fitting curve (line)

Figure 3 : Time-resolved transient absorption spectra recorded at different delays after $532 \mathrm{~nm}$ laser pulse excitation of deaerated acetonitrile solution containing $\mathrm{EO}^{2-}$ $\left(5 \times 10^{-6} \mathrm{M}\right)$ and $\mathrm{nBu}_{4} \mathrm{~N}, \mathrm{BF}_{6}\left(10^{-2} \mathrm{M}\right)$

Figure 4: Time-resolved transient absorption spectra recorded at different delays after $532 \mathrm{~nm}$ laser pulse excitation of deaerated acetonitrile solution containing $\mathrm{EO}^{2-}$ $\left(5 \times 10^{-6} \mathrm{M}\right), \mathrm{AgNO}_{3}\left(2.5 \times 10^{-4} \mathrm{M}\right)$ and $\mathrm{nBu}_{4} \mathrm{~N}, \mathrm{BF}_{6}\left(10^{-2} \mathrm{M}\right)$

Inset : Absorption-time profile recorded at $450 \mathrm{~nm}$

Figure 5: Evolution of the absorption spectra of two irradiated mixtures in acetonitrile $\left(\lambda_{\text {irr }}=534 \mathrm{~nm}\right)$. Solution $\mathbf{A}: \mathrm{EO}^{2-}\left(10^{-5} \mathrm{M}\right), \mathrm{AgNO}_{3}\left(5 \times 10^{-4} \mathrm{M}\right)$ and $\mathrm{Bu}_{4} \mathrm{~N}_{,} \mathrm{BF}_{6}$ $\left(10^{-2} \mathrm{M}\right)$; Solution $\mathbf{B}: \mathrm{EO}^{2-}\left(10^{-5} \mathrm{M}\right), \operatorname{AgNO}_{3}\left(5 \times 10^{-4} \mathrm{M}\right)$, MDEA $\left(10^{-2} \mathrm{M}\right)$ and $\mathrm{nBu}_{4} \mathrm{~N}, \mathrm{BF}_{6}\left(10^{-2} \mathrm{M}\right)$

Figure 6 : Time-resolved transient absorption spectra recorded at different delays after $532 \mathrm{~nm}$ laser pulse excitation of deaerated acetonitrile solution containing $\mathrm{EO}^{2-}$ $\left(5 \times 10^{-6} \mathrm{M}\right), \mathrm{AgNO}_{3}\left(2.5 \times 10^{-4} \mathrm{M}\right), \operatorname{MDEA}\left(5 \times 10^{-3} \mathrm{M}\right)$ and $\mathrm{nBu}_{4} \mathrm{~N}, \mathrm{BF}_{6}\left(10^{-2}\right.$ M) 
Figure 7 : TEM image of silver nanoparticles embedded in pentaerythritol triacrylate $\left(\mathrm{AgNO}_{3}, 1 \mathrm{wt} \%\right)$.

Inset : Growth of the absorption spectrum of Ag nanoparticles (optical path of the cuvette $: 1 \mathrm{~cm}$ )

Figure 8 : Real-time FTIR kinetics conversion curves for visible-curing at $532 \mathrm{~nm}$ of resins with (1) $\mathrm{EO}^{2-} / \mathrm{MDEA}, 0.1 \mathrm{wt} \% / 3$ wt \% (2) $\mathrm{EO}^{2-} / \mathrm{MDEA} / \mathrm{AgNO}_{3}$, 0.1 wt $\% / 3$ wt $\% / 1$ wt $\%$ Inset : View of $30 \mu \mathrm{m}$ thick samples (1) and (2) after curing

Figure 9: Time evolution of the absorption spectrum of the resin during photopolymerization $\mathrm{EO}^{2-/} \mathrm{MDEA} / \mathrm{AgNO}_{3}, 0.1 \mathrm{wt} \% / 3 \mathrm{wt} \% / 1$ wt \% (optical path of the cuvette : $30 \mu \mathrm{m}$ ) Inset : Linear correlation between absorption at $532 \mathrm{~nm}$ and $432 \mathrm{~nm}$

Figure 10: (A) Kinetics of absorption at $432 \mathrm{~nm}$ for various samples with increasing amounts of $\mathrm{EO}^{2-}\left(\mathrm{MDEA} / \mathrm{AgNO}_{3}, 3 \mathrm{wt} \% / 1 \mathrm{wt} \%\right)$. (B) Correlation between the final absorbance of plasmon band with the initial amount of $\mathrm{EO}^{2-}$

Figure 11: TEM image of silver nanoparticles embedded in a polyacrylate matrix, with their respective size distribution. $\mathrm{EO}^{2-} / \mathrm{MDEA} / \mathrm{AgNO}_{3}$ : (a) $0.06 \mathrm{wt} \% / 3 \mathrm{wt}$ $\% / 1 \mathrm{wt} \%$ and (b) $0.28 \mathrm{wt} \% / 3 \mathrm{wt} \% / 1 \mathrm{wt} \%$

Scheme 1: Structures of pentaerythritol triacrylate (PETA) and of Eosin Y disodium salt 


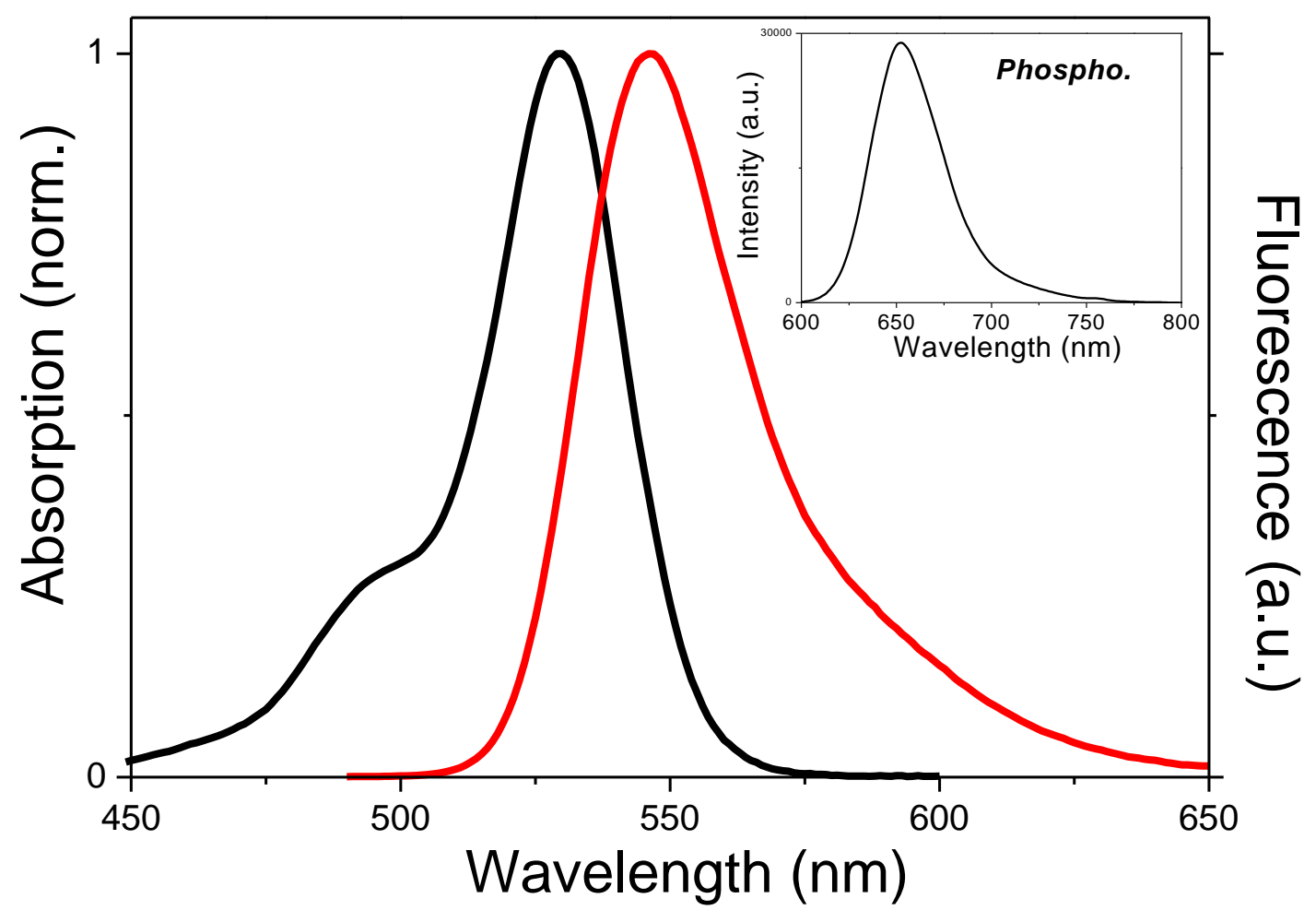

Figure 1 


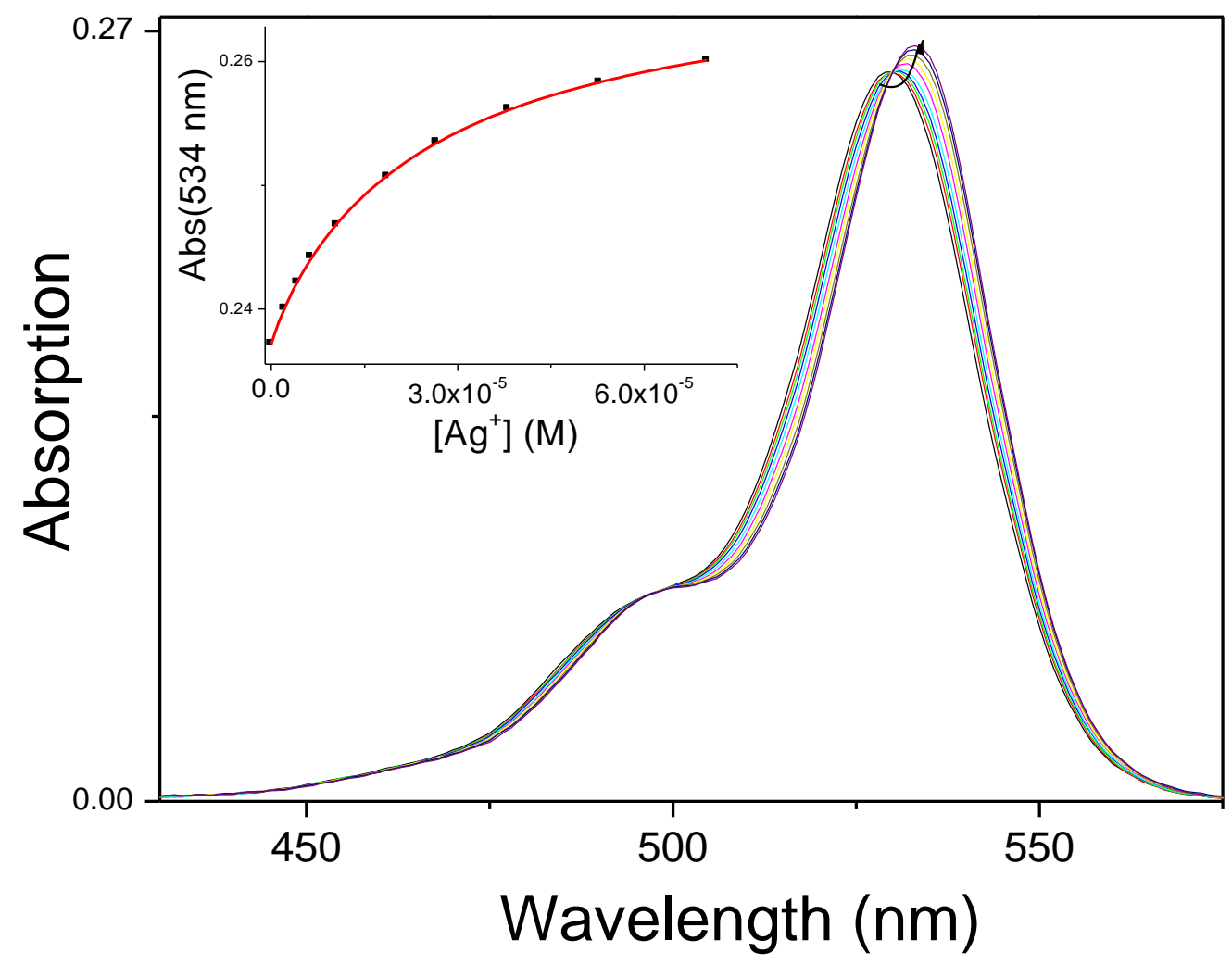

Figure 2 


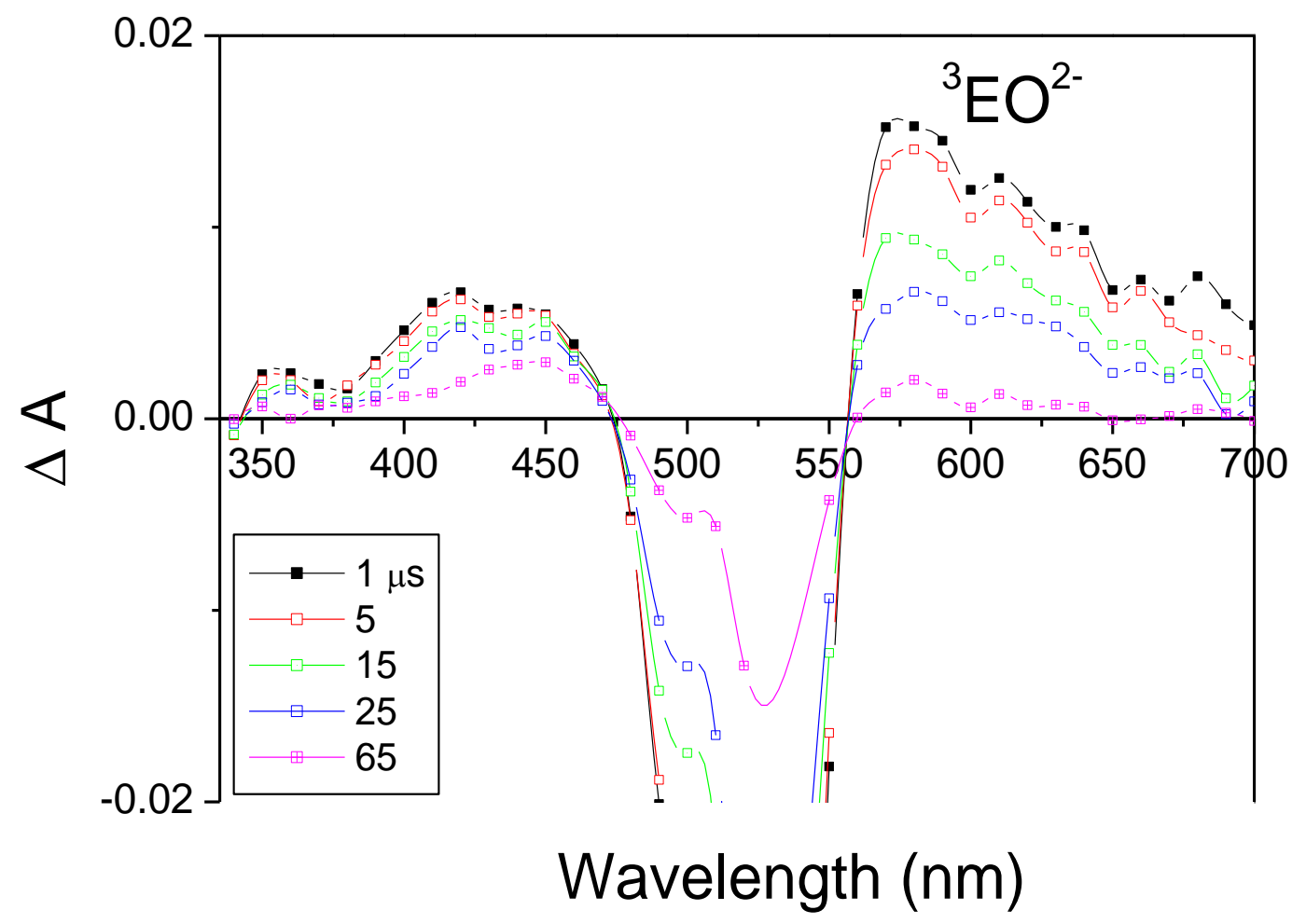

Figure 3 


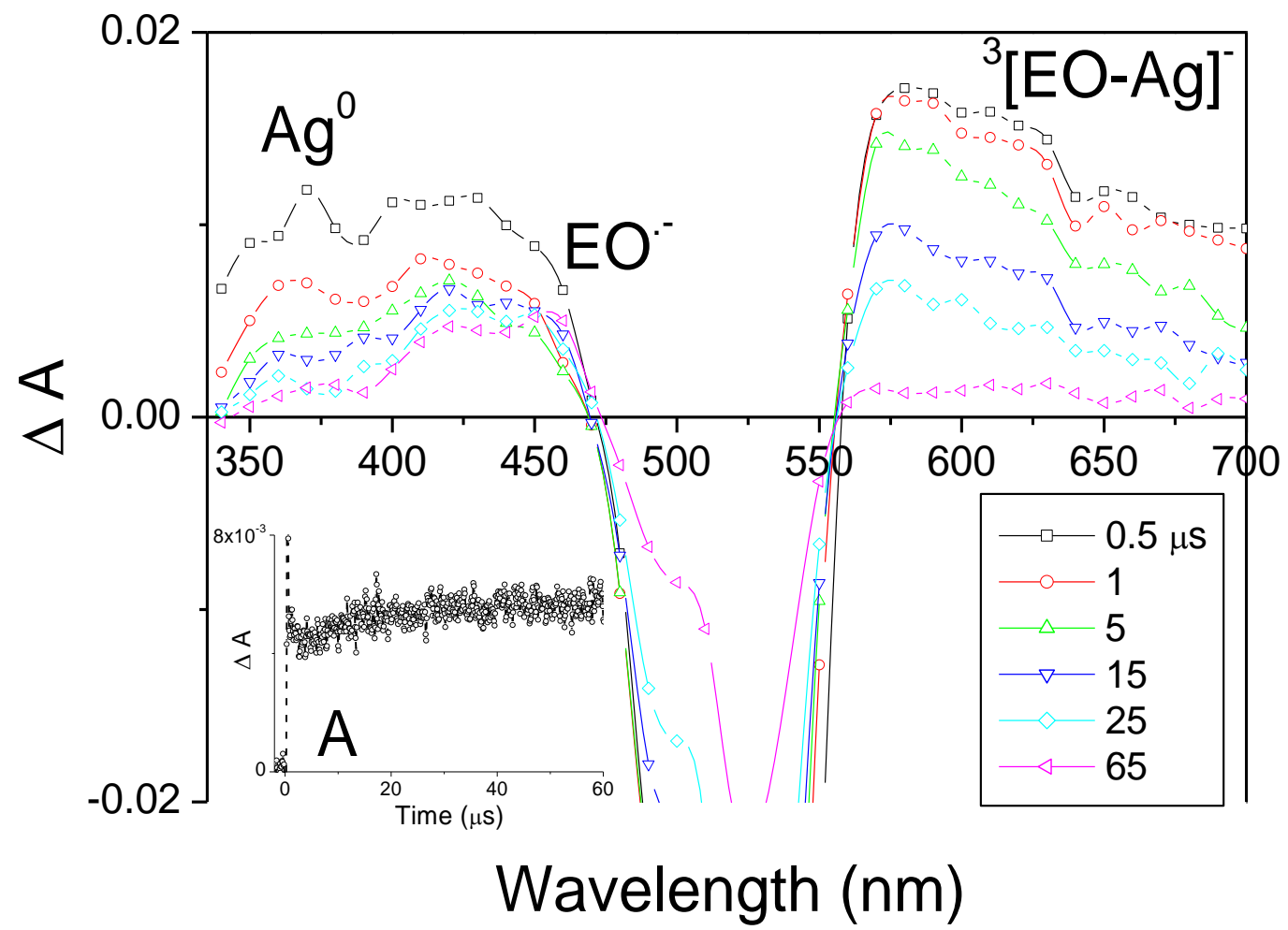

Figure 4 


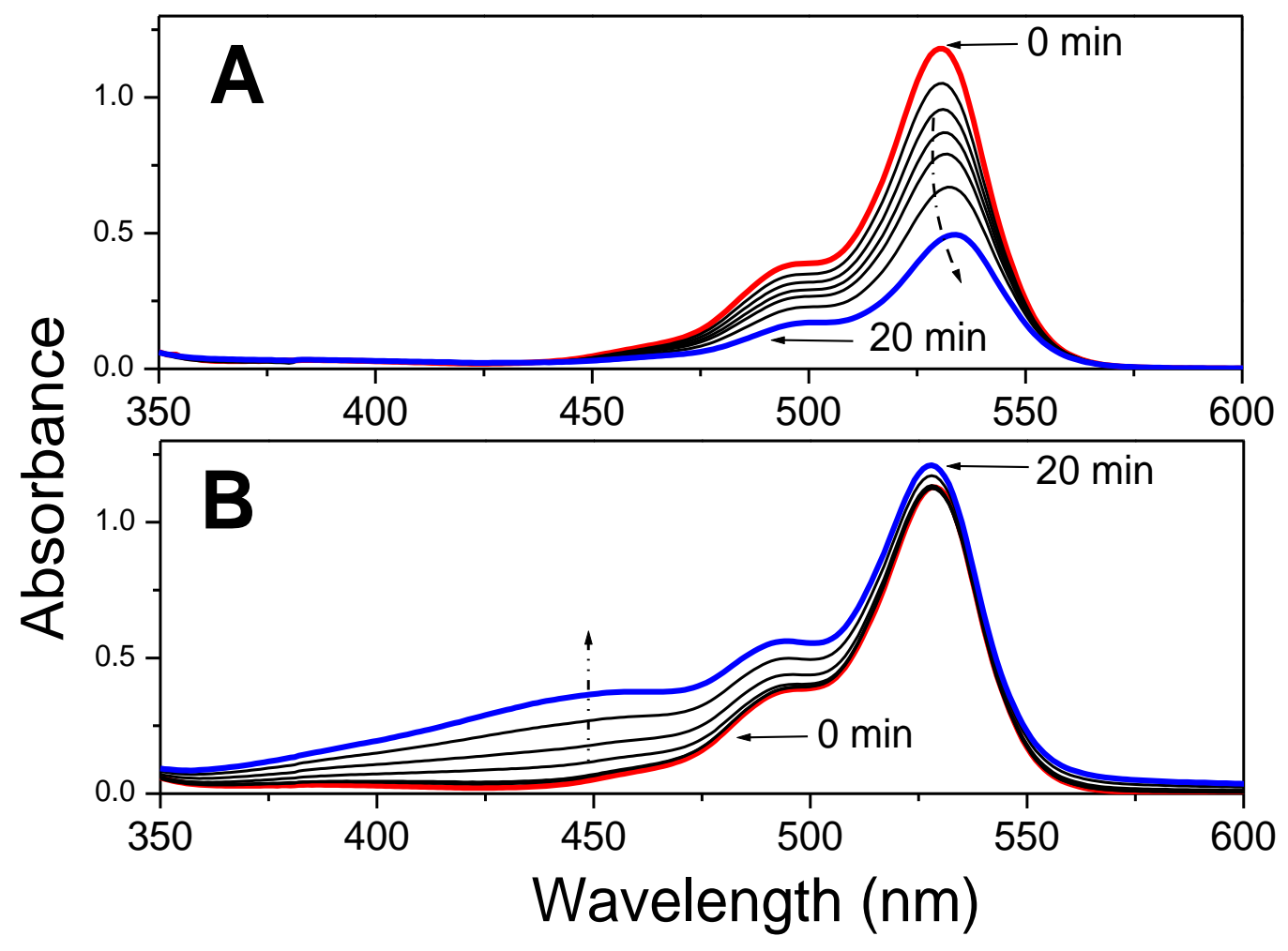

Figure 5 


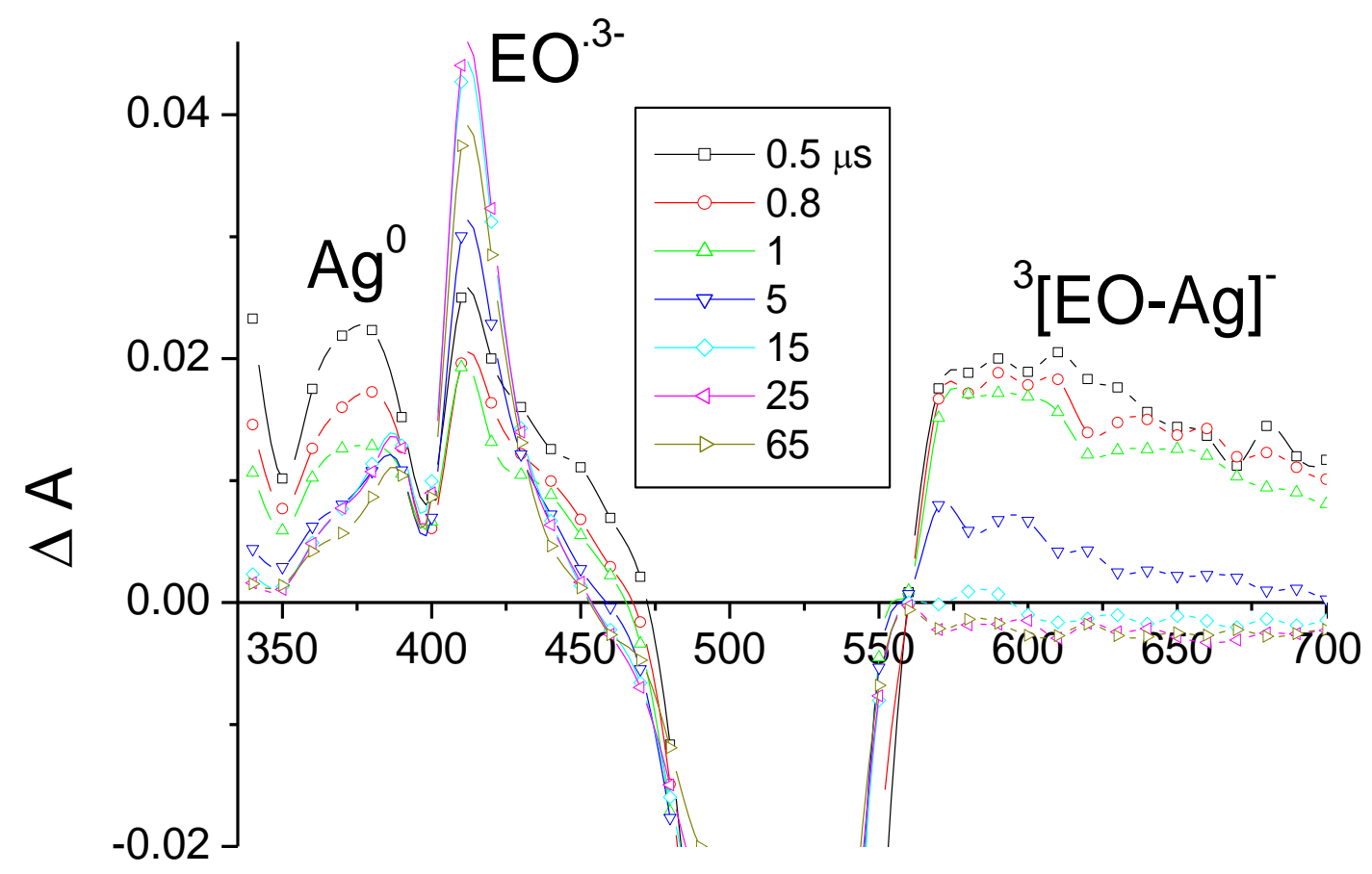

Wavelength $(\mathrm{nm})$ 


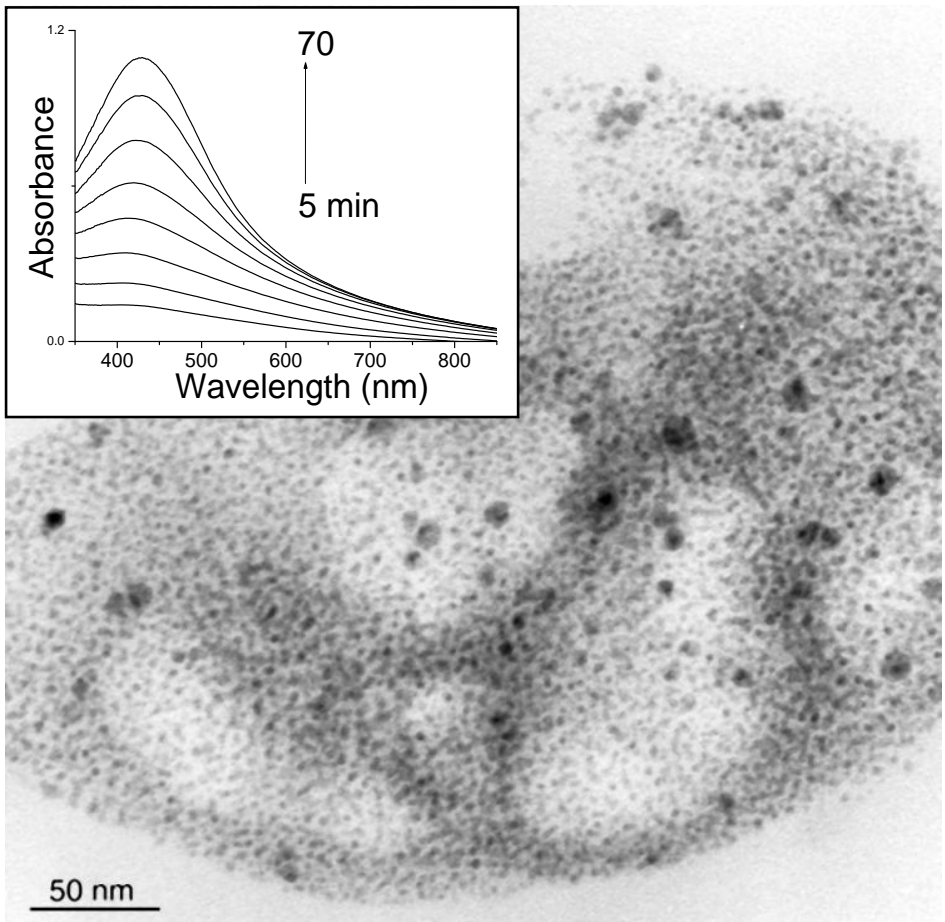

Figure 7 


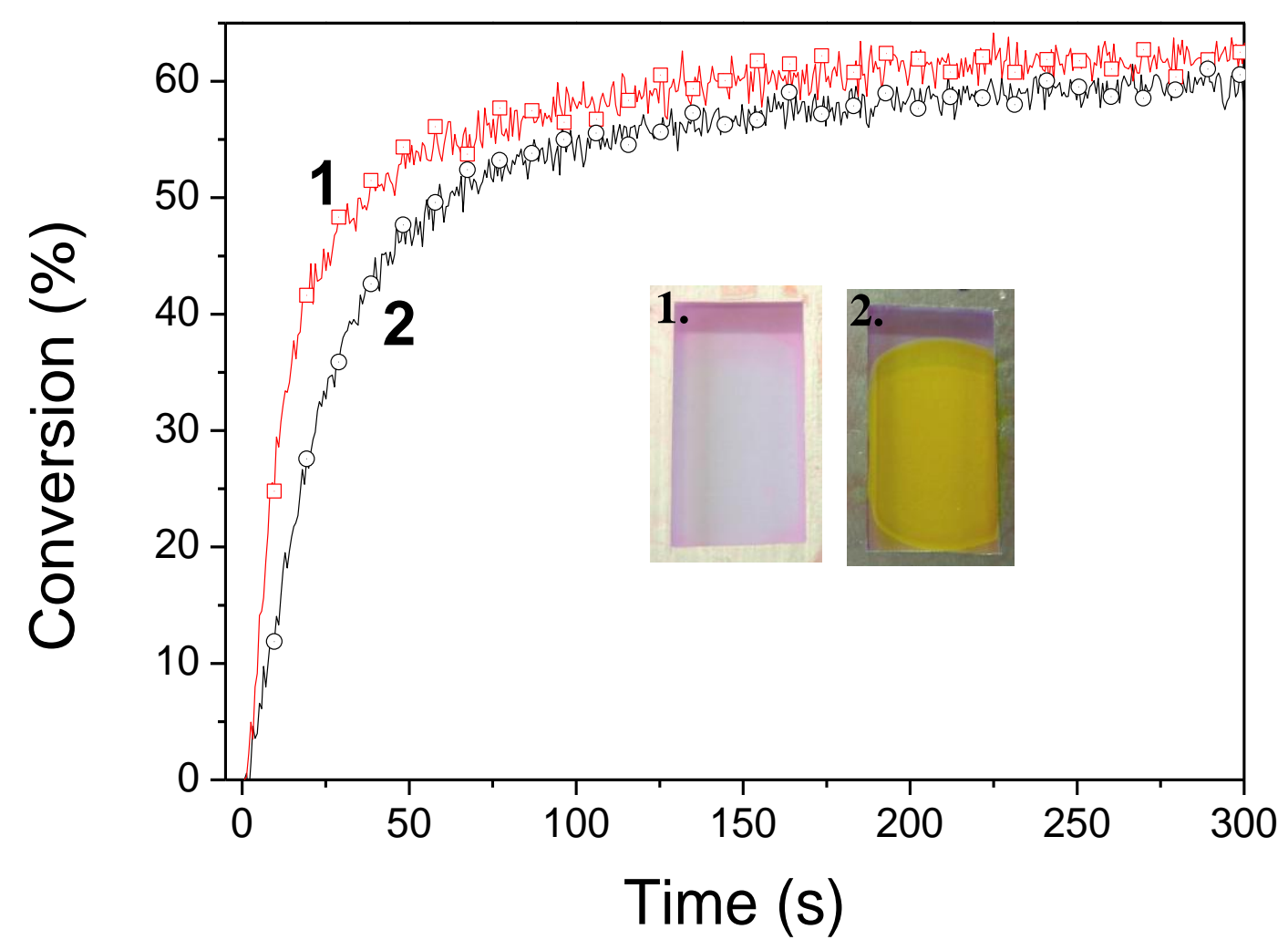

Figure 8 


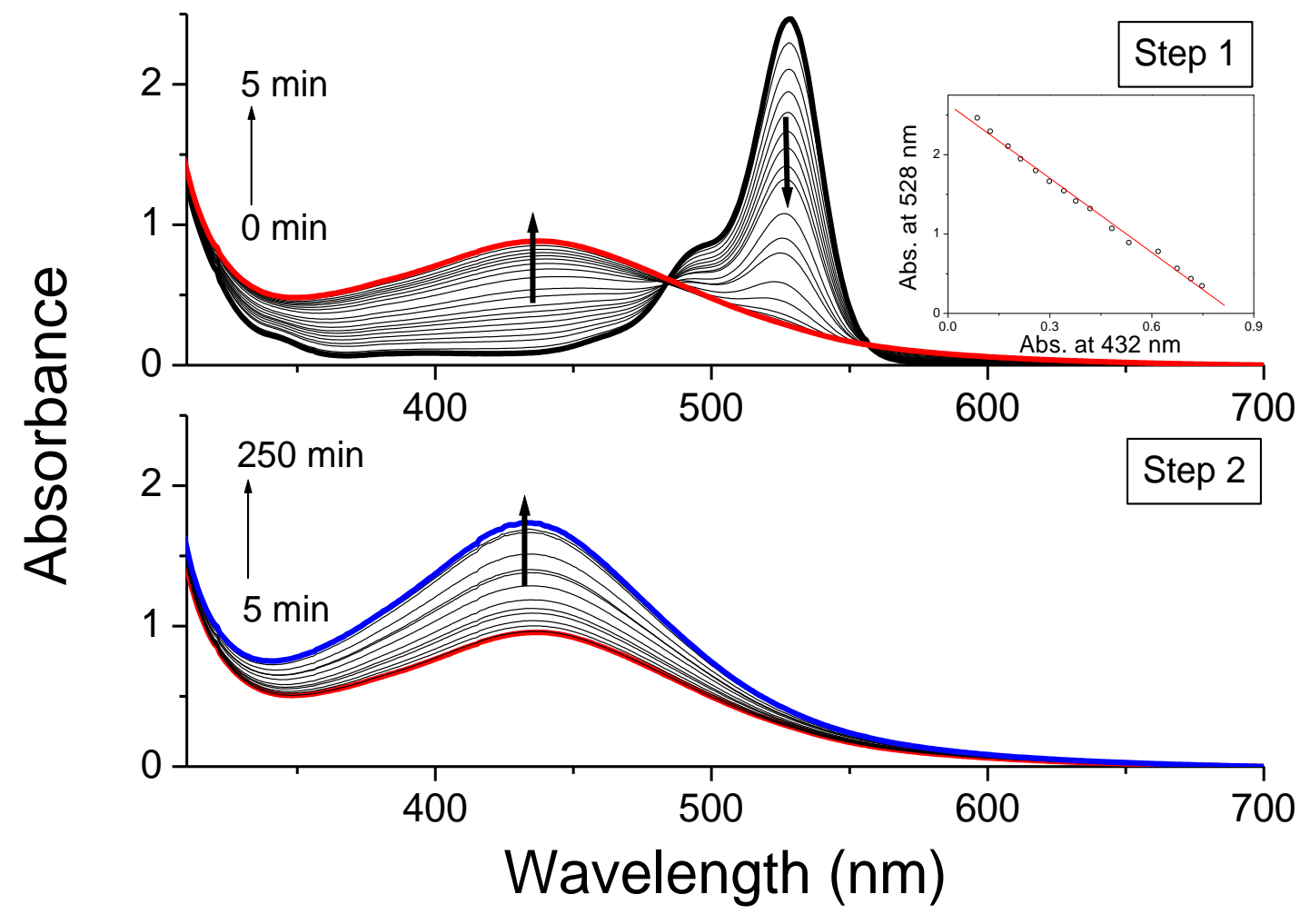

Figure 9 

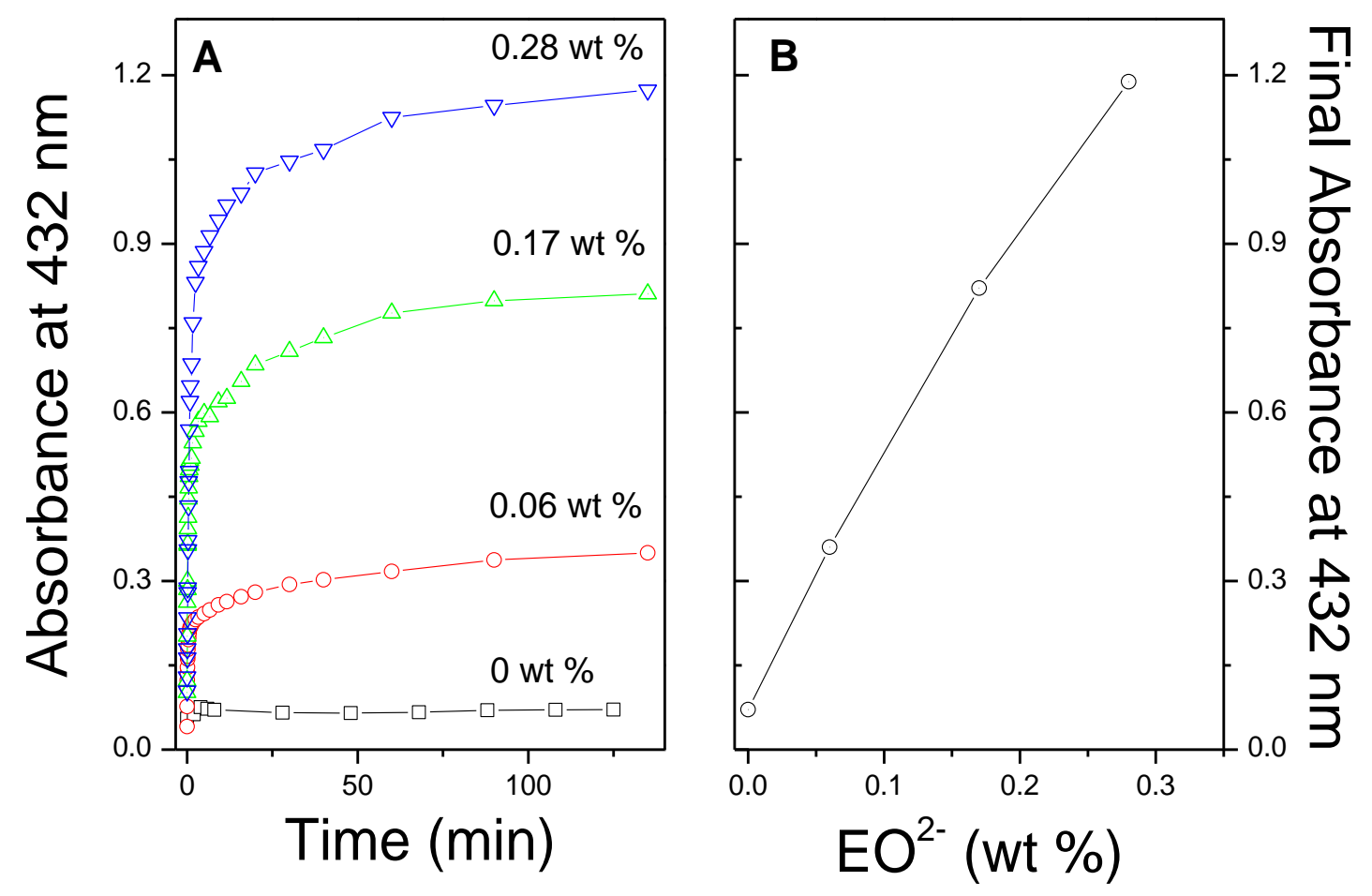

Figure 10 

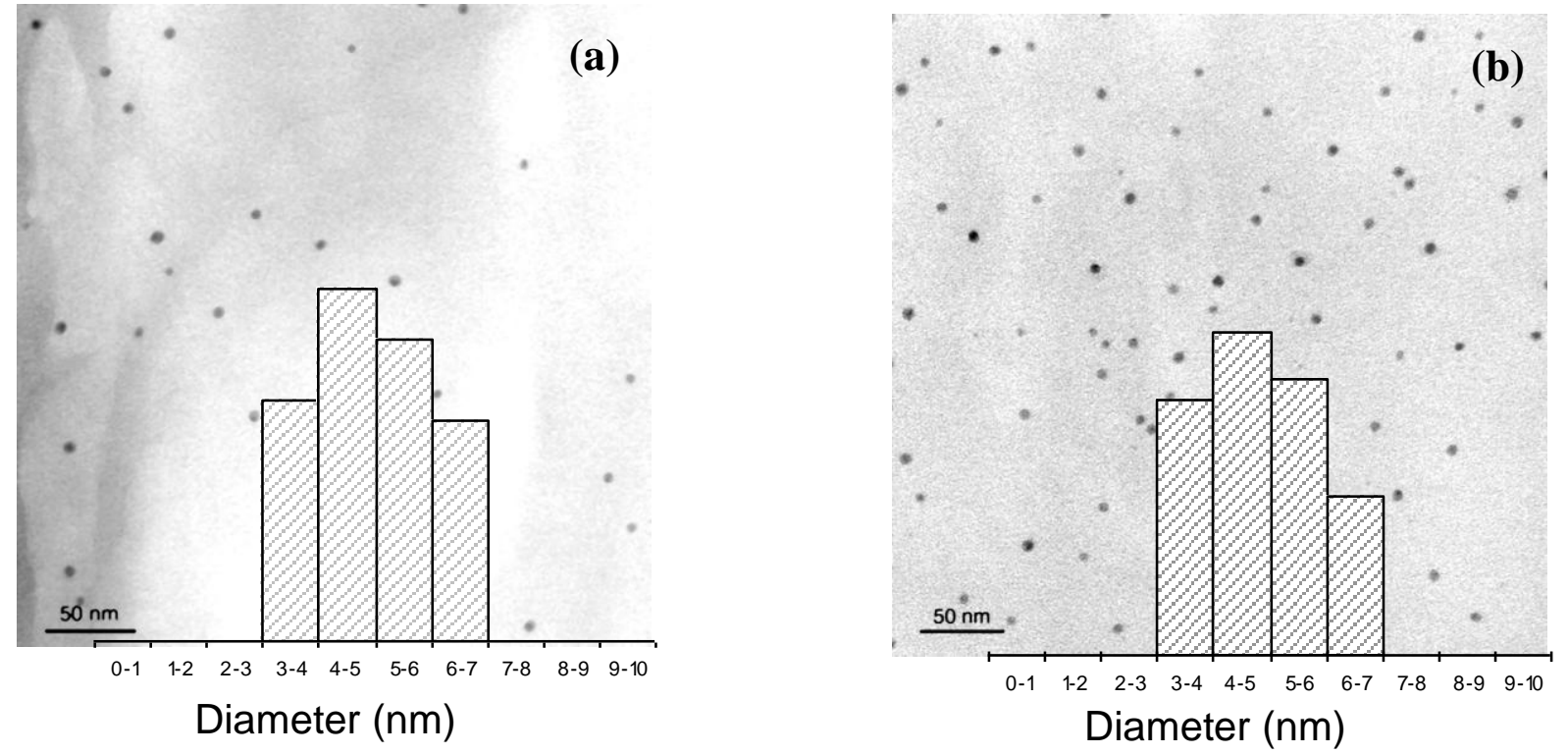

Figure 11 

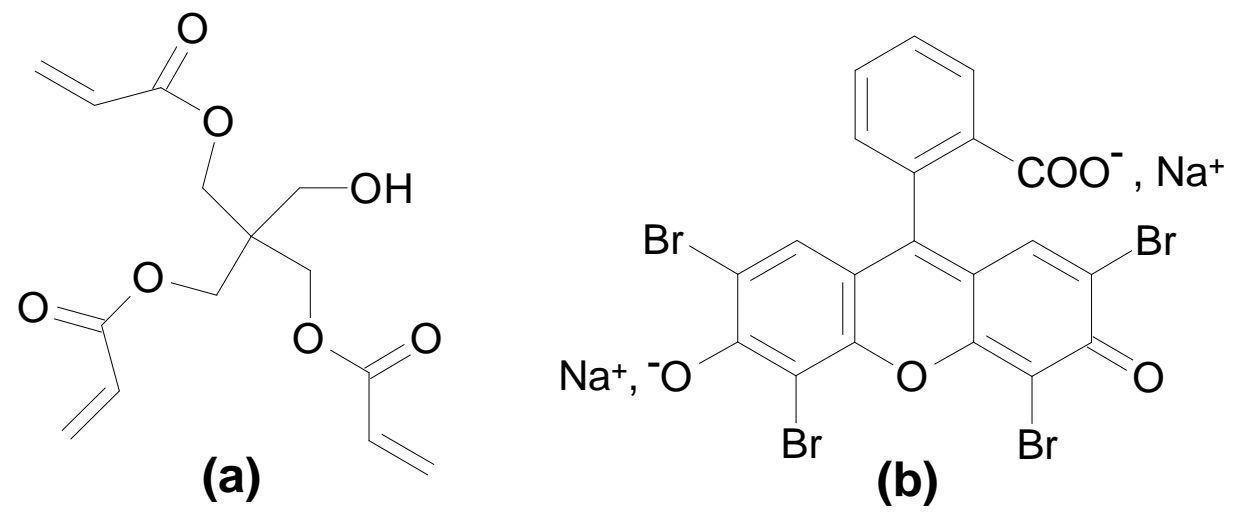

Scheme 1 